\title{
Patients with third degree burns in an emergency department
}

\author{
Tamer Durdu' $^{1}$ D , Ahmet Burak Erdem
AD, E
Alp Şener ${ }^{2}$ (D),
1 Ankara City Hospital, Department of Emergency Medicine, Ankara, Turkey. \\ 2 Yıldırım Beyazıt University Faculty of Medicine, Department of Emergency Medicine, Ankara, Turkey.
}

\begin{abstract}
Background: Skin protects the body against external factors, helps maintain physiological body temperature, and has sensory and immune functions. Burns can occur with electricity, radiation, chemicals, hot and cold factors. Since this is a very important public health problem, we aimed to analyze the epidemiological data of third-degree burns with high risk of mortality and morbidity in our emergency department.
\end{abstract}

Methods: Retrospectively, 73 patients with third-degree burns between January 2011 and December 2012 were included in the study. Demographic data of the patients, location and percentage of burn, cause, and mortality were recorded. Data between genders analyzed statistically.

Results: $79.5 \%$ of the patients were male. The mean age was $35 \pm 18$ years. Flame burns were most common. It was determined that male patients had longer hospital stays. There was no statistically significant difference between age and gender in terms of mortality. It was observed that mortality increased as the percentage of burns increased.

Conclusion: Third-degree burns are the most common cause of burns with flame, as in young adult males. While there is no difference in mortality between age and gender, the death rate increases as the burn area increases. The frequency of burns can be reduced if the society is educated about protective measures against flammable and combustible materials. Thus, the bad results that may occur due to burns can be reduced. Therefore, regional epidemiological studies are needed.

Keywords: Third Degree Burn, Emergency Department, Epidemiology. 


\section{INTRODUCTION}

Burns occur when the skin is damaged, which can extend from the epidermis to the bone tissue, caused by the heat generated by flammable and caustic substances. Burns are graded according to the affected layer of the skin. According to this classification, third-degree burns involve all layers of the epidermis and dermis (1-2).Scalding is caused by flame, electricity, radiation and chemical substances.Flame burns cause especially deep and third degree burns.After the burns occur, it continues to be an important health problem due to the additional problems it brings in the healing process.In addition to medical and surgical applications, psychological and visual problems significantly affect the family as well as the patient (2). Burns are the fourth most common cause of trauma affecting humans, with 11 million cases worldwide each year. According to the World Health Organization, more than 300,000 people die from burns. This problem is more common in countries that are below the development chart (3-4). It is estimated that $1 \%$ of all people may experience a severe burn once in their lifetime (5). Burn data may contain regional differences. The socio-economic status of the regions may cause changes in data such as the causes and frequency of burns (6). In this study, we aimed to examine the mortality and morbidity of patients who were presented to the emergency department of our hospital with isolated or mosaic type third degree burns. We believe that the results obtained can provide important data in taking precautions to prevent the burn formation mechanism and planning treatment centers.

\section{MATERIALS AND METHODS}

Our study was carried out with the decision numbered E-19-2652 of the ethics committee of Ankara Numune Training and Research Hospital. It was carried out in accordance with the Declaration of Helsinki and good clinical practices. There is no conflict of interest between the authors. Our study was planned as a retrospective observational. Patient consent was not obtained because it was in the form of a file review over the hospital automation system and did not contain images that would enable patients to be identified.

Patients with third-degreeburnsadmitted to ouremergency department between January 2011 and December 2012 were evaluated retrospectively. The files of 81 patients who presented to the emergency department with burns, including isolated and mosaic type third-degree burns, were analyzed.73 patients were included in the study. Eight patients were excluded due to missing data.A form was prepared for the study. Demographic data, burn site, cause of burn, burn percentage, length of hospital stay and mortality status of the patients included in the study were recorded in this form. The latest status of the patients was followed up via the hospital information system (e-pulse). Data were recorded by 2 emergency medicine specialists. The other 2 emergency medicine specialists checked the data. The patients were divided into 2 groups as male and female. The relationship between age, burn site, percentage, cause, length of hospital stay and in-hospital mortality results was statistically analyzed between the groups. The percentage of burns was calculated according to the rule of 9s. According to the 9's rule, the head and neck are $9 \%$, the trunk is $18 \%$, the back is $18 \%$, each of the arms is $9 \%$, the perineum is $1 \%$, and each of the legs is $18 \%(7)$.

This study was approved by the clinical research ethics committee of the Health Sciences University, Ankara Numune Training and Research Hospital (Date: 18.04.2019 number: 2652) and written consent was obtained from all patients participating in the study.

\section{Statistical Analysis}

Statistical analysis were made with IBMSPSS for Windows 16.0 Package Program. Frequency distributions of ordinal data were made with Pearson Chi-Square and Fisher's Exact tests.Distribution analysis of continuous data was made with the Shapiro-Wilk test, and the Mann Whitney-U test was used to compare the medians of the data that did not fit the normal distribution between the two groups. As a result of this test, the median, IQR, minimum and maximum values of the data are given.The Independent Samples-t test was used for comparisons of the two-group mean on data with normal distribution, and the results were expressed as mean and standard deviation.The $p$ value was used for statistical significance and a $p<0.05$ level was considered significant.

\section{RESULTS}

$79.5 \%$ of the patients were male and the mean age was $35 \pm 18$ years, and $9(12.3 \%)$ patients died in the hospital within 30 days (Table-1).The mean duration of hospitalization was calculated as $27 \pm 23$. The distribution of the patients according to the burn site and type of burn is shown in Table-1.Flame, electricity and hot water burns 
are seen to apply frequently.The mean percentage of total body burns of the patients was $25 \%$ and the percentage of third degree burns was $12 \%$.Although the mortality rate in women was higher than in men, but this difference was not statistically significant ( $12.1 \%$ vs $13.3 \%$; $\mathrm{p}=1,000$ ). Although the age was higher in the mortality group, no statistically significant difference was found (Median: 36 vs 32; $\mathrm{p}=0.425)$. Mortality percentages according to burn site and type are given in Table-2. As expected, the percentage of total burns and third-degree burns were found to be significantly higher in the mortality group (Table-3).Among all patients, it was found that the mean age was statistically significantly higher in female patients, and the mean burn percentages and hospitalization times were significantly higher in male patients (Table-4).The distribution in terms of burn location and type by gender is given in Table-5, and the order of frequency in male patients is flame, electrical and hot liquid burns, while in female patients it occurs as hot liquid, flame and solid contact burns (Table-5).

Table 1. Distribution of general data of patients

\begin{tabular}{|c|c|c|c|c|c|}
\hline & & $\begin{array}{l}\text { Line- } \\
\mathbf{N}(\%)\end{array}$ & Mean \pm SD & Median (IQR) & Min-max \\
\hline Condo & Male & $58(79.5)$ & & & \\
\hline Gender & Female & $15(20.5)$ & & & \\
\hline Age & & & $35 \pm 18$ & $32(22-44)$ & $1-85$ \\
\hline Hospital s & & & $27 \pm 23$ & $18(10-42)$ & $0-97$ \\
\hline 1. & Alive & $64(87.7)$ & & & \\
\hline Mortality & Exitus & $9(12.3)$ & & & \\
\hline & Widespread body involvement & $5(6.8)$ & & & \\
\hline & Head-neck+Trunk+extremity & $12(16.4)$ & & & \\
\hline & Head-neck+Trunk+extremity+Perineum & $3(4.1)$ & & & \\
\hline Burn site & Head-neck+extremity & $3(4.1)$ & & & \\
\hline Burn site & Head-neck+extremity+Perineum & $2(2.7)$ & & & \\
\hline & Trunk+extremity & $9(12.4)$ & & & \\
\hline & Trunk+extremity+Perineum & $2(2.7)$ & & & \\
\hline & extremity & $37(50.7)$ & & & \\
\hline & Widespread body involvement & $5(6.8)$ & & & \\
\hline & Head-neck & $20(27.4)$ & & & \\
\hline Burn site & Trunk front back & $26(35.6)$ & & & \\
\hline & Upper-Lower extremity & $67(93.2)$ & & & \\
\hline & Perineum & $7(9.6)$ & & & \\
\hline & Explosion & $4(5.5)$ & & & \\
\hline & Flame burn & $24(32.9)$ & & & \\
\hline & Electrical burn & $18(24.7)$ & & & \\
\hline Type of & Thinner burn & $4(5.5)$ & & & \\
\hline burn & Solid contact burn & $3(4.1)$ & & & \\
\hline & Hot liquid burn & $15(20.5)$ & & & \\
\hline & Dull burn & $3(4.1)$ & & & \\
\hline & Chemical burn & $2(2.7)$ & & & \\
\hline Percentage & 3rd degree burn & & $12 \pm 16$ & $5(3-15)$ & $1-65$ \\
\hline Burn perce & age of total body burn area & & $25 \pm 24$ & $18(7-40)$ & $1-100$ \\
\hline
\end{tabular}


Table 2. Distribution of patients by gender, burn site and type according to mortality.

\begin{tabular}{|c|c|c|c|}
\hline & & \multicolumn{2}{|c|}{ Mortality } \\
\hline & & Alive & Exitus \\
\hline & & $\begin{array}{l}\text { Line- } \\
\mathbf{N}(\%)\end{array}$ & $\begin{array}{l}\text { Line- } \\
\mathbf{N}(\%)\end{array}$ \\
\hline \multirow{2}{*}{ Gender } & Male & $51(87.9)$ & $7(12.1)$ \\
\hline & Female & $13(86.7)$ & $2(13.3)$ \\
\hline \multirow{8}{*}{ Burn site } & Widespread body involvement & $2(40)$ & $3(60)$ \\
\hline & Head-neck+Trunk+Extremity & $8(66.7)$ & $4(33.3)$ \\
\hline & Head-neck+Trunk+Extremity+Perineum & $3(100)$ & $0(0)$ \\
\hline & Head-neck+Extremity & $3(100)$ & $0(0)$ \\
\hline & Head-neck+Extremity+Perineum & $2(100)$ & $0(0)$ \\
\hline & Trunk+Extremity & $8(88.8)$ & $1(11.2)$ \\
\hline & Head-neck+Extremity+Perineum & $2(100)$ & $0(0)$ \\
\hline & Extremity & $36(97.3)$ & $1(2.7)$ \\
\hline \multirow{5}{*}{ Burn site } & Widespread body involvement & $2(40)$ & $3(60)$ \\
\hline & Head-neck & $16(80)$ & $4(20)$ \\
\hline & Trunk front-back & $21(80.8)$ & $5(19.2)$ \\
\hline & Upper-Lower extremity & $62(91)$ & $6(9)$ \\
\hline & Perineum & $7(100)$ & $0(0)$ \\
\hline \multirow{8}{*}{ Type of burn } & Explosion & $2(50)$ & $2(50)$ \\
\hline & Flame burn & $21(87.5)$ & $3(12.5)$ \\
\hline & Electrical burn & $18(100)$ & $0(0)$ \\
\hline & Thinner burn & $1(25)$ & $3(75)$ \\
\hline & Solid contact burn & $3(100)$ & $0(0)$ \\
\hline & Hot liquid burn & $14(93.3)$ & $1(6.7)$ \\
\hline & Dull burn & $3(100)$ & $0(0)$ \\
\hline & Chemical burn & $2(100)$ & $0(0)$ \\
\hline
\end{tabular}

Table 3. Distribution of patients by age, length of hospital stay and percentage of burns by mortality.

\begin{tabular}{|c|c|c|c|c|c|}
\hline & \multicolumn{5}{|c|}{ Mortality } \\
\hline & \multicolumn{2}{|c|}{ Alive } & \multicolumn{2}{|c|}{ Exitus } & \multirow{2}{*}{ p-value } \\
\hline & Mean \pm SD & Median (IQR) & Mean \pm SD & Median (IQR) & \\
\hline Age & $34 \pm 18$ & $32(22-43)$ & $41 \pm 21$ & $36(26-47)$ & 0.425 \\
\hline Hospital stay & $30 \pm 23$ & $20(14-44)$ & $5 \pm 4$ & $4(2-7)$ & $<0.001$ \\
\hline 3rd degree burn percentage & $7 \pm 7$ & $5(3-10)$ & $47 \pm 16$ & $50(40-60)$ & $<0.001$ \\
\hline $\begin{array}{l}\text { Total Body Burn Area burn } \\
\text { percentage }\end{array}$ & $20 \pm 18$ & $15(6-29)$ & $66 \pm 22$ & $70(45-80)$ & $<0.001$ \\
\hline
\end{tabular}


Table 4.Distribution of patients by age, length of stay and burn percentage by gender

\begin{tabular}{|c|c|c|c|c|c|}
\hline & \multicolumn{4}{|c|}{ Gender } & \multirow{3}{*}{ P-value } \\
\hline & \multicolumn{2}{|c|}{ Male } & \multicolumn{2}{|c|}{ Female } & \\
\hline & Mean \pm SD & Median (IQR) & Mean \pm SD & Median (IQR) & \\
\hline Age & $31 \pm 14$ & $30(21-39)$ & $50 \pm 25$ & $49(28-73)$ & $0.013^{*}$ \\
\hline Hospital stay & $30 \pm 24$ & $21(12-45)$ & $11 \pm 9$ & $12(2-15)$ & $0.003^{* *}$ \\
\hline 3rd degree burn percentage & $13 \pm 16$ & $6(3-15)$ & $9 \pm 15$ & $3(1-8)$ & $0.034^{* *}$ \\
\hline $\begin{array}{l}\text { Total Body Burn Area burn } \\
\text { percentage }\end{array}$ & $28 \pm 24$ & $20(8-44)$ & $16 \pm 20$ & $8(4-26)$ & $0.024^{* *}$ \\
\hline $\begin{array}{l}\text { *Independent Samples-t test } \\
\text { **Mann Whitney-U test }\end{array}$ & & & & & \\
\hline
\end{tabular}

Table 5. Distribution of burn site and type of patients by gender

\begin{tabular}{|c|c|c|c|}
\hline & & \multicolumn{2}{|c|}{ Gender } \\
\hline & & Male & Female \\
\hline & & Count & Count \\
\hline \multirow{8}{*}{ Burn site } & Widespread body involvement & $5(8.6)$ & $0(0)$ \\
\hline & Head-neck+Trunk+Extremity & $10(17.2)$ & $2(13.3)$ \\
\hline & Head-neck+Trunk+Extremity+Perineum & $3(5.2)$ & $0(0)$ \\
\hline & Head-neck+Extremity & $2(3.4)$ & $1(6.7)$ \\
\hline & Head-neck+Extremity+Perineum & $2(3.4)$ & $0(0)$ \\
\hline & Trunk+Extremity & $9(15.5)$ & $0(0)$ \\
\hline & Trunk+Extremity+Perineum & $1(1.7)$ & $1(6.7)$ \\
\hline & Ekstremity & $26(44.8)$ & $11(73.3)$ \\
\hline \multirow{8}{*}{ Type of burn } & Explosion & $4(6.9)$ & $0(0)$ \\
\hline & Flame burn & $21(36.2)$ & $3(20)$ \\
\hline & Electrical burn & $17(29.3)$ & $1(6.7)$ \\
\hline & Thinner burn & $4(6.9)$ & $0(0)$ \\
\hline & Solid contact burn & $0(0)$ & $3(20)$ \\
\hline & Hot liquid burn & $7(12.1)$ & $8(53.3)$ \\
\hline & Dull burn & $3(5.2)$ & $0(0)$ \\
\hline & Chemical burn & $2(3.4)$ & $0(0)$ \\
\hline
\end{tabular}

\section{DISCUSSION}

In our study, we found that the patients with third-degree burns who applied to the emergency department due to burns were mostly young adult males and the most common cause was flame burn. When the burn area of the patients was examined, we saw that the extremities burned more. Burns continue to be an important health problem in our country. With the developing treatment methods and the establishment of burn centers, the mortality rate in burns is also decreasing. In the study conducted by Açıel et al. in the first burn center of Istanbul, it was determined that burns were seen in men with a rate of $81 \%$ (8).In our study, $79.5 \%$ of the patients were male.In the study of IIlhan et al., $78.2 \%$ of the patients were male. Halk et al. reported 68\%, Demirel et al. 61.7\%, and Pal et al. $71.68 \%$ burns in men (9-11). It is seen that burns are more common in men than women, but the rates vary according to regions and countries. In our study, it shows 
similarity with the literature by drawing a more intense profile in men. Considering the age distribution in these studies, it was seen that the most affected group was in the 20-50 age range (8-11). In our study, we found the mean age to be $35 \pm 18$ years and it was similar to the literature. When the burn sites were examined, it was seen that there was an effect on the extremities of all patients. The rate of burns limited only to the extremities was $50.7 \%$. In other patients, in addition to extremity burns, torso, head-neck and perineal regions were accompanied. 5 patients had burns in all parts of the body.It was observed that these burns were respectively caused by flame, electricity and hot liquid (32.9-24.7-20.5\%).The mechanism of burns was flame burns in $36.2 \%$ of men and electrical burns of $29.3 \%$, while hot liquid burns in $53.3 \%$ of women.We think that this difference between the sexes is due to the fact that men work with machinery and in places such as industry with flammable-burning and electricity, while women deal with jobs that provide more contact with hot water at home.All results suggest that people do not take protective measures during operations with flammable and combustible materials and that their extremities are tried to be used to reduce the effect of burning. These results were similar to other studies in our study. İlhan et al., in their study, found that the most common type of burn was flame burns, followed by electrical and scalding burns $(53.7 \%, 30.0 \%, 11.8 \%$, respectively).It was found that men were exposed to flame and electric burns $(50.0 \%$ and $38.4 \%$, respectively), while women were exposed to flame and scalding (66.6\% and $29.1 \%$, respectively) burns (12). In a study conducted in Morocco, it was shown that flame burns were the most common cause of burns $(45.6 \%)$ and that $93.1 \%$ of all patients were affected by thermal burns (13).Considering the percentage of total burns affected by the patients, the average burn area was $25 \%$, while the average area affected by third degree burns was $12 \%$. While the total burn area was $100 \%$ in only one of our patients, the third degree burn area was $60 \%$. This patient died on the second day of hospitalization. Calder found the mean total body burn area to be $19 \%$ in his study in Afghanistan (14). In the study in which Özçetin et al. shared their 2.5year experience, the burn area of the patients was found to be $30 \%$ or less in $97 \%$ of the patients (15).These results are consistent with the data in our study.12.3\% of the patients in our study died. Although the mortality rate in women was higher than in men, no statistically significant difference was found.13.3\% of women and $12.1 \%$ of men died. Although the age of the deceased group was high in the patients who died, it did not create a statistically significant difference. In the study of Shir Khoda et al., the mortality rate was found to be $41.47 \%$, and Verma et al. found $36.5 \%$ (16,17).In the study of Ho et al., the mortality rate was found to be $2.3 \%$ (18).The reason for the difference between the studies may be due to the high burn rate of the patients in the studies of Shirkhoda and Verma, and the fact that the burn area in most patients was less than $10 \%$ in the study of Ho.Considering the results in our study, it was seen that the death rate increased as the burn area increased. The mean area of third-degree burns in deceased patients was $47 \%$, while the total burn area was $66 \%$. This rate was found to be significant in terms of the relationship between survivors.Other studies and our results showed that the death rate increased with the increase in burn area.When Song et al. looked at the duration of hospital stay, they found an average of 28.67 days in patients with a burn area of $30 \%$ or more (19).Jayaraman et al. showed that $19.2 \%$ of patients hospitalized for burns were hospitalized for longer than 15 days (20).In our study, the average total burn area was $25 \%$ and the average hospital stay was 27 days. The mean hospital stay was 30 days in surviving patients, and 5 days in deceased patients. We think that this result is due to the fact that burn treatment causes long-term hospitalizations. As a result; In third-degree burn cases, men are mostly affected and flame and burns are the most common factors. In women, burns are more common with hot liquids. While the death rate increases as the burn area increases, there is no difference between age and gender.Burns continue to be an important health problem in terms of mortality and morbidity, although we encounter different data even in the same geography.However, its incidence can be reduced with effective preventive measures.Programs and plans can be made for raising awareness and education of the society in terms of public health. For this, more regional epidemiological studies are needed.

\section{Declarations}

The authors received no financial support for the research and/or authorship of this article. There is no conflict of interest.

This study was approved by the clinical research ethics committee of the Health Sciences University, Ankara Numune Training and Research Hospital (Date: 18.04.2019 number: 2652) and written consent was obtained from all patients participating in the study. 


\section{REFERENCES}

1. Özkaya NK, Alğan S, Akkaya H. Assessment and Defining the Treatment of the Patients with Burns. Ankara Med J. 2014;14(4):170-175.

2. Koltka K. Burn Injuries: Burn Depth, Physiopathology and Type of Burns. Journal of the Turkish Society of Intensive Care. 2011;9(Special Issue):1-6.

3. Peck MD. Epidemiology of burns throughout the world. Part I: distribution and risk factors. Burns. 2011; 37:1087-1100.

4. Smolle C, Cambiaso-Daniel J, Forbes AA, Wurzer P, Hundeshagen G, Branski LK et al. Recent trends in burn epidemiology worldwide: a systematic review. Burns. 2017; 43:249-257.

5. Organization WH. A WHO plan for burn prevention and care. Bull World Health Organ. 2008; 87:802-803.

6. Davé DR, Nagarjan N, Canner JK, Kushner AL, Stewart BT; SOSAS4 Research Group. Rethinking burns for low \& middle-income countries: Differing patterns of burn epidemiology, care seeking behavior, and outcomes across four countries. Burns. 2018;44(5):1228-1234.

7. Yoshino Y, Ohtsuka M, Kawaguchi M, Sakai K, Hashimoto A, Hayashi Met al. The wound / burn guidelines-6: Guidelines for the management of burns. J Dermatol. 2016;43(9):989-1010.

8. Açıkel C, Peker F, Yüksel F, Ülkür E, Kale B. 734 Akut yanıklı sivil ve asker hastanin retrospektif analizi. Türk Plast Rekonstr Est Cer Derg. 2001;9(2):111-115.

9. Haik J, Liran A, Tessone A, Givon A, Orenstein A, Peleg K; et al. Burns in Israel: demographic, etiologic and clinical trends, 1997-2003. Isr Med Assoc J. 2007;9(9):659-62.

10. Demirel Y, Cöl C, Özen M. Evaluation of the Patients Treated in the Ankara Numune Hospital Burn Centre in One Year. C. Ü. Tıp Fakültesi Dergisi.2001;23(1):15-20.

11. Pal N, Jain U, Mishra V, Poonam, Jangra A. Analysis of incidence, etiology and risk factors associated in acute burns injury in adults. International Journal of Surgery Science. 2019;3(3):65-67.

12. İlhan E, Cengiz F, Demirkıran MA, Yılmaz S, Deneçli AG. Evaluation of our 15-month experience in the Izmir Bozyaka Education and Research Hospital Burn Unit. Ulusal Cerrahi Dergisi. 2011;27(3):154-158.

13. Achbouk A, Boufars A, Zrara A, Bouaiti E, Ribag Y, Siah S, Elkafssaoui S. Epidemiological Analysis of Burn Patients in Morocco: About 160 Cases. IOSR-JDMS. 2019;18(2):76-79.

14. Calder F. Four years of burn injuries in a Red Cross hospital in Afghanistan. Burns. 2002; 28:563-568.

15. Özçetin B, Tihan D, Demirci H, Altıntaş MM, Arayıcı V, Taha A. Two and a half years experience at a new burn center. Ulusal Cerrahi Dergisi. 2012;28(3):146-148.

16. Shirkhoda M, Kaviani Far K, Narouie B, Shikhzadeh A, Ghasemi Rad M, Hanfi Bojd H. Epidemiology and Evaluation of 1073 Burn Patients in the Southeast of Iran. Shiraz E-Medical Journal. 2011;12(1):11-21.

17. Verma SK, Chaturvedi S, Gupta S. A sociodemographic profile and outcome of burn patients admitted in a tertiary-care hospital. International Journal of Medical Science and Public Health. 2016;5(11):2290-2293.

18. Ho W, Ying SY. An epidemiological study of 1063 hospitalized burn patients in a tertiary burns centre in Hong Kong. Burns. 2001; 27:119-123.

19. Song C, Chua A. Epidemiology of burn injuries in Singapore from 1997 to 2003. Burns. 2005; 31S:S18-S26.

20. Jayaraman V, Ramakrishnan KM, Davies MR. Burns in Madras, India: an analysis of 1368 patients in 1 year. Burns. 1993;19(4):339-344. 